This is a self-archived version of an original article. This version may differ from the original in pagination and typographic details.

Author(s): Salo, Markus; Makkonen, Markus

Title: Why Do Users Switch Mobile Applications? : Trialing Behavior as a Predecessor of Switching Behavior

Year: 2018

Version: Published version

Copyright: ㄷ Association for Information Systems, 2018

Rights: In Copyright

Rights url: http://rightsstatements.org/page/InC/1.0/?language=en

Please cite the original version:

Salo, M., \& Makkonen, M. (2018). Why Do Users Switch Mobile Applications? : Trialing Behavior as a Predecessor of Switching Behavior. Communications of the Association for Information Systems, 42, Article 14. https://doi.org/10.17705/1CAIS.04214 


\section{Communications of the Association for Information Systems}

Volume 42

Article 14

$4-2018$

\section{Why Do Users Switch Mobile Applications? Trialing Behavior as a Predecessor of Switching Behavior}

Markus Salo

University of Jyväskylä, markus.t.salo@jyu.fi

Markus Makkonen

University of Jyväskylä

Follow this and additional works at: http://aisel.aisnet.org/cais

\section{Recommended Citation}

Salo, Markus and Makkonen, Markus (2018) "Why Do Users Switch Mobile Applications? Trialing Behavior as a Predecessor of Switching Behavior," Communications of the Association for Information Systems: Vol. 42 , Article 14.

DOI: $10.17705 / 1$ CAIS.04214

Available at: http://aisel.aisnet.org/cais/vol42/iss1/14

This material is brought to you by the AIS Journals at AIS Electronic Library (AISeL). It has been accepted for inclusion in Communications of the Association for Information Systems by an authorized administrator of AIS Electronic Library (AISeL). For more information, please contact elibrary@aisnet.org. 


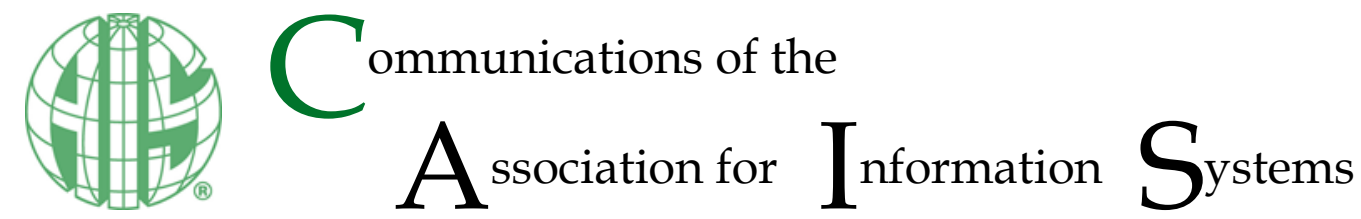

Research Paper

DOI: 10.17705/1CAIS.04214

ISSN: 1529-3181

\title{
Why Do Users Switch Mobile Applications? Trialing Behavior as a Predecessor of Switching Behavior
}

\author{
Markus Salo \\ Faculty of Information Technology \\ University of Jyväskylä \\ markus.t.salo@jyu.fi
}

\author{
Markus Makkonen \\ Faculty of Information Technology \\ University of Jyväskylä
}

Abstract:

Mobile application providers face high user losses because users can easily and often switch to an alternative application. Researchers have recently started to study information technology (IT) switching. However, no studies have concentrated on the unique context of mobile applications. Mobile application switching differs from the switching behavior related to many other IT products and services because of the highlighted role of alternatives, beta versions, updates, reviews, and users' spontaneous behavior. To address this gap, we develop a mobile-specific model by using a qualitative research approach. As a theoretical contribution, we introduce trialing behavior as a predecessor of switching behavior and present six new behavioral antecedents for them. As practical implications, we suggest ways for mobile application providers and developers to reduce user churn.

Keywords: Mobile Applications, Switching Behavior, Trialing Behavior, IT Use.

This manuscript underwent peer review. It was received 05/03/2017 and was with the authors for 6 months for 1 revision. Devinder Thapa served as Associate Editor. 


\section{Introduction}

Mobile applications, as software applications that run on mobile or tablet devices, play a key role in today's information technology (IT) industry (Chandra, Srivastava, \& Theng, 2010; Zein, Salleh, \& Grundy, 2016). However, mobile application providers and developers struggle with trying to keep their users over time because users of mobile applications can easily and often switch to an alternative. As Apple Store and Google Play each offer more than two million mobile applications available for consumers (Statista, 2016), a competing alternative for almost every application regardless of its type seems to exist. For example, users have the freedom to choose their favorites from hundreds of sports-tracking, weatherforecasting, or instant-messaging applications. Recently, millions of users switched (temporarily or permanently) to an alternative instant messaging application because market-leader WhatsApp suffered a several-hour outage (Mashable 2014). Therefore, because user switching significantly impacts mobile application providers' success, they need to understand the reasons why users switch (Bansal, Taylor, \& James, 2005; Xu, Yang, Cheng, \& Lim, 2014).

Compared to physical products and services, switching IT is often considered simpler: similar alternatives are easy to find, they are accessible just one click away with no extra effort, and users may use multiple alternatives simultaneously (Bhattacherjee, Limayem, \& Cheung, 2012; Ye, Desouza, Sangareddy, \& Jha, 2008). Moreover, mobile application switching involves several special characteristics when compared to the switching behavior of many other IT products and services: a vast number of free or inexpensive alternatives for mobile applications usually exist (Zhou, 2011), mobile application providers typically rush to markets with unfinished beta versions, mobile applications and operation systems often have rapid update cycles (Zein et al., 2016), the reviews in mobile application marketplaces can have a significant influence on user behavior, and users also tend to be more spontaneous with mobile applications than with other types of IT products and services (Anckar \& D'Incau 2002). Therefore, by understanding the critical drivers of mobile application switching, application providers can improve their chances for maintaining longer customer relationships and gaining a competitive advantage in an overcrowded, dynamic, and hypercompetitive market (Merali, Papadopoulos, \& Nadkarni, 2012; Xu, Yang, Cheng, \& Lim, 2014). In such markets, providers and companies are typically forced to shift their focus "from customer acquisition to customer retention" (Shoemaker \& Lewis, 1999, p. 346).

Researchers have recently started to study IT switching. The main body of IT switching research has focused on identifying issues that influence switching behavior positively or negatively. Examples of recurrent findings include dissatisfaction with the current IT (positive influence on switching), attractiveness of the alternative IT (positive influence on switching), and switching costs (negative influence on switching). By identifying such issues, researchers have been able to offer theoretical and practical implications about the main drivers of IT switching. Prior research has examined switching in multiple contexts, such as Web browsers, social networking sites, games, and blogs. However, we could not locate any studies that have examined switching in the specific context of mobile applications-a gap in prior research on switching behavior due to the numerous special characteristics of the mobile application context that we discuss above. Even though some of these characteristic individually apply also to other types of IT products and services, the combination of them makes the context of mobile application switching a unique one.

In this paper, we address this gap in prior research by developing a context-specific model for explaining mobile application switching because context-specific approaches are "vital in providing a rich understanding of a focal phenomenon and to meaningfully extend theories" (Venkatesh, Thong, \& Xu, 2012, p. 158). Thus, we examine the research question (RQ):

RQ: Why do users switch mobile applications?

To answer this question, we conducted a study with a qualitative research approach since qualitative research methods enable researchers to better attain context-specific insights of an uncovered phenomenon and explain IT use in real-life situations (Berg, 2004; Venkatesh, Brown, \& Bala, 2013).

As a theoretical contribution, this study presents a new context-specific model that explains mobile users' switching behavior. Importantly, we introduce trialing behavior as a central, yet previously uncovered, predecessor of switching behavior. The discovery of trialing behavior offers a new and valuable perspective: during trialing behavior, mobile application providers may still have time to retain their users before losing them entirely to competitors. Our model suggests a total of 11 issues that act as antecedents for switching and trialing behavior. According to our literature review, six of these issues are 
new and have not been presented in prior studies on IT switching. Thus, our study extends the current knowledge by presenting novel explanations for why mobile application providers lose their users to the competitors. In doing so, our study also contributes to practice by pointing out crucial issues that mobile application providers and developers can take on to reduce user switching and churn ${ }^{1}$.

\section{Background}

The literature contains established theories that predict which general constructs influence IT adoption, use, and use continuance (e.g., Bhattacherjee, 2001; Davis, 1989; DeLone \& McLean, 2003; Rogers, 1995; Venkatesh, Morris, Davis, \& Davis, 2003). These theories, which have often originated from reference disciplines such as psychology and sociology, have been valuable in advancing our knowledge on an abstract level. During the last decades, numerous researchers have frequently applied the theories, especially to inspect IT users' behavioral intentions.

However, the maturation of the major stream of IT usage research has generated (at least) two calls for further research. First, in contrast to abstract theorizing, researchers have encouraged others to concentrate on more context-specific and in-depth approaches to increase the practical impact of research (Grover, 2014; Grover \& Lyytinen, 2015). Second, so far, researchers have focused heavily on use continuance but paid less attention to the other important post-adoption behaviors, such as switching and word of mouth (Kim \& Son, 2009). Therefore, we extend the current knowledge of IT usage by generating a mobile-specific model to explain one common type of post-adoption behavior: users' switching behavior.

\subsection{Studies on Individual IT Users' Switching Behavior}

We define IT users' switching behavior, in accordance with Bhattacherjee et al. (2012, p. 327), as "complete or partial replacement of the use of one IT product or service with a substitute that serves similar needs". We reviewed relevant empirical studies that focused on issues that influence individual users' switching of IT products or services. We excluded studies that examined other than the level of individual users (e.g., organizations switching of software vendors) from this review. We conducted keyword searches by using different combinations of the following terms: information, technology, IT, mobile, application, switch, and switching. We also searched backward and forward from the citations of the discovered papers. To complement our search, we assigned a task similar to our review to a graduate student who worked on a thesis on IT switching. One of the authors instructed the student about the inclusion/exclusion criteria, keywords, and sources. While every review may "miss some articles" (Webster \& Watson, 2002, xvi), we focused on ensuring that our review included relevant papers that examined IT switching. The Appendix summarizes the previous studies on IT switching that we found in terms of their research contexts, applied theories, and key findings.

Research interest in IT switching has recently grown. Most IT switching studies have investigated issues that either enable or inhibit users' switching intentions. Users make their switching decisions based on the issues that draw them towards an alternative IT and the issues that favor their current IT. Researchers have investigated these two types of issues by using similar theories, such as the most frequently applied push-pull-mooring theory based on Bogue (1969), Lee (1966), and Bansal et al. (2005). During the last few years, researchers have managed to study IT switching in several contexts, such as Web browsers (Ye et al., 2008), portals (Kim \& Son, 2009), online shopping (Zhou, 2014), social networking sites (Wu, Tao, Li, Wang, \& Chiu, 2014), mobile devices (Hsu, 2014), online games (Hou, Chern, Chen, \& Chen, 2011), e-mail (Kim, Shin, \& Lee, 2006), and blog providers (Zhang, Lee, Cheung, \& Chen, 2009).

Many of the IT switching studies have used rather abstract constructs that could be applied to almost all (IT) contexts. For example, some of the most recurrent issues that researchers have found to influence switching include (dis)satisfaction with the current IT (e.g., Bhattacherjee et al., 2012; Lin \& Huang, 2014; Ye et al., 2008), attractiveness of the alternative IT (e.g., Chang, Liu, \& Chen, 2014; Lai, Debbarma, \& Ulhas, 2012; Xu et al., 2014), switching costs (Fei \& Bo, 2014; Wu, Tao, Li, Wang, \& Chiu, 2014; Zhou, 2014), and social influence (Bhattacherjee \& Park, 2014; Polites \& Karahanna, 2012; Ye \& Potter, 2011).

\footnotetext{
${ }^{1}$ From the perspective of mobile application providers, users' switching behavior is undesirable (although this assumption does not indicate that providers should reduce user churn at any cost). However, switching may have several benefits from the individual users' perspective, but those aspects do not fall in this paper's scope.
} 
This approach of using rather abstract constructs has been particularly useful in providing "a starting point for furthering our understanding of IT switching" (Bhattacherjee et al., 2012, p. 327).

However, in order to dive deeper and provide more accurate and practically relevant results, researchers have begun to call for more context-specific switching research that accounts for the characteristics of the particular IT in question (Xu et al., 2014; Zhang et al., 2012). As an example, Zhang et al. (2012) have uncovered blog-specific issues such as blog storage capacity, readership, and blogging culture. Yet, we seem to lack previous studies and context-specific insights about mobile application switching.

In sum, the previous studies on the topic offer a valuable overview of the general drivers of IT switching, but they do not present any context-specific insights about mobile application switching. More precisely, they have not covered the important aspects that are specific for mobile applications (numerous free or inexpensive alternatives, application providers' rush to markets with unfinished beta versions, reviews in application marketplaces, users' more spontaneous behavior, and rapid update cycles). For example, Google recently announced that the YouTube mobile application would no longer support Apple mobile devices with old iOS operating systems, which caused many users to have to switch to an alternative application (CNet, 2015). Therefore, by investigating the context of mobile applications, we can contribute to the IT switching literature through generating new context-specific knowledge for researchers (Venkatesh et al. 2012) and offering practical implications for mobile application providers in order to reduce user churn.

\section{Method}

Answering our research question required data that reflects 1) the context-specific characteristics of mobile application switching and 2) users' actual real-life experiences of mobile application switching. Therefore, we chose to employ a qualitative research approach because researchers have found such an approach as useful for uncovering context-specific insights and generating explanations of IT use in reallife situations (Berg, 2004; Venkatesh et al., 2013). In this way, we could also minimize the risks of speculating about unfamiliar or hypothetical scenarios that do not necessarily reflect real-life IT use (van der Heijden, 2012). To remain focused on our context-specific data, we did not preselect any strict theoretical framework for the empirical part of the study but let our review of the prior studies inform our analysis when appropriate. Finally, we generated a reflective comparison of our resulting model and prior IT switching studies, which we present in Section 5.

\subsection{Data Collection}

In total, we collected data from 54 individual users of various mobile applications in three phases. Archetypal to many qualitative studies, we focused on finding information-rich users for the purpose of each phase instead of gathering a fully generalizable sample (Patton, 1990). During the research process, we used theoretical sampling: we initially collected data regarding a wider problem (mobile application users' negative experiences), but then we recognized the need to focus on one of the key outcomes of negative experiences (mobile application switching).

In the first phase, we derived our initial data set from a larger survey that we conducted to understand mobile application users' highly negative experiences. Since we noted that only a small fraction of the users complained about their highly negative experiences to the application providers, we became interested in seeking the reasons for such non-complaining behavior. Thus, we sent two open-ended follow-up questions (i.e., "Which reasons have affected you not to complain to the application provider?" and "How did it affect you that the application in question is mobile and not another type of a service or product?") by email for all of those respondents who, in that survey, permitted email enquiries and stated that they had undergone an outstandingly negative experience with a mobile application but had not complained about it. We received responses (averaging approximately half a page of written text) from 22 of the approached 36 users. As application switching emerged as one of the primary and recurrent answers, we used this data set to form initial reasons for switching and as inspiration to conduct more indepth investigations.

In the second phase, we collected our main data to get deeper insights about these particular reasons. We conducted interviews of 18 Finnish mobile application users throughout 2013 to 2015. Our recruiting these interviews did not relate to our previous survey. Instead, we deliberately sought users who could provide first-hand experiences of the post-adoption use and switching of mobile applications. For example, we used the snowballing technique to gather a pool of information-rich interviewees (Patton, 
1990). To reach multiple views about the topic, we picked interviewees varying in terms of age, gender, primary socioeconomic status, field of business, and IT experience. However, because we did not seek generalizability as a main goal for our study, we did not focus on perfectly balancing the sample in terms of these or other variables in order to achieve statistical representativeness. We conducted the interviews so that they were based on the users' actual experiences. Further, to ensure we could address the focus of this study (i.e., why users switch IT applications), we asked the users to describe their concrete examples of mobile application switching in as detailed form as possible. In order to elaborate the users' practices and perceptions, we asked several specific questions about how and why their switching situations had originated and taken place. We followed Myers and Newman's (2007) main guidelines for interviewing: for instance, we focused on minimizing social dissonance by appearing trustworthy and diplomatic, on staying flexible and open towards emerging themes, and on using the mirroring technique. We also recorded the interviews, which lasted approximately 40 minutes on average, and transcribed the relevant parts. In this phase, we noted that some of the issues have different kinds of relationships with switching-some enable it while others inhibit it.

In the third phase, we again used our previous larger survey sample to contact a different set of respondents and to saturate our findings. Thus, we sent open-ended follow-up emails for respondents who had not been involved in the first or second phase of this study. We approached users from different age, gender, and education groups. Of the 26 approached users, 14 submitted responses (averaging over half a page of written text). In order to continue theoretical sampling, we had framed two open-ended questions as follows:

Considering (free or bought) mobile applications downloaded from the marketplace (e.g., Apple App Store and Google Play), please describe as detailed as possible:

\section{What kinds of issues enable you to switch an application to an alternative?}

\section{What kinds of issues inhibit you from switching an application to an alternative?}

Overall, we believe that we reached a sufficient level of saturation to identify why users switch mobile applications: in the third data set, we did not find new information that would have significantly changed the overall results. Altogether, the age of the 54 informants ranged from 16 to 66 (11 informants (20.4\%) were 24 years old or under, 22 informants (38.9\%) were between 25 and 34 years old, 15 informants $(27.8 \%)$ were between 35 and 44 years old, and seven informants (13\%) were 45 years old or over). Thirty-four $(63 \%)$ of the informants were men and twenty (37\%) were women. The informants had varying socioeconomic statuses (e.g., employed, unemployed, and student). Their experience and skills with IT also varied. The users' mobile applications reflected non-work and non-organizational purposes (e.g., sports tracking, music streaming, and instant messaging) - in line with our focus on consumer applications that highlight the voluntariness of switching behavior.

\subsection{Data Analysis}

To ensure the fit between the data and the emerging model, we collected and analyzed the data iteratively: we constantly compared whether new data complemented, modified, or challenged our earlier analyses (Berg, 2004). Based on this comparison, we refined the emerging model. Our unit of analysis was individual users, which means that we studied users' perceptions on mobile application switching.

First, we started by focusing on the data and used coding (Berg, 2004; Glaser \& Strauss, 1967) to label our interview and open-ended email data in NVivo. The first author read and reread the data and, based on the keywords and phrases from the data, attached descriptive labels for the relevant sets of words, sentences, or sets of sentences that reflected switching behavior. The second author conducted author checks in order to confirm that the labels matched the data. Altogether, this coding resulted in a total number of 359 text instances with 28 labels as subcategories (examples include easy to search, easy to download, and easy to install). Next, the first author related the subcategories to each other and sorted them into compiling categories based on the data. As Berg (2004) suggests, the first author combined the codes that included similar keywords or phrases and labeled them with descriptive category names. For example, the first author interpreted easy to search, easy to download, and easy to install as subcategories of a broader category labeled low search and setup costs. To ensure the appropriateness of this sorting approach, the first author used hand-written notes and involved the second author in decisions about sorting the labels and attaching them with the category names (Berg, 2004). When necessary, we also revisited the sorting until we reached a mutual agreement. As a result, we identified 12 categories that influenced switching behavior. During this analysis, we let the reviewed prior studies 
support the labeling of the categories (as other authors suggest, such as Urquhart \& Fernandez, 2013). Seven of our total 12 categories (see Table 1) included content that we could not identify from prior IT switching studies. Therefore, we attached the seven categories with names based on our data. The content of the remaining five categories, however, included similar aspects that prior IT switching studies have found. Thus, we adapted the names for those five categories from prior studies on IT switching.

Then, we focused on understanding the relationships between the categories. As Berg (2004) advises, we did so by focusing on the recurrent patterns in the data, discussing the category connections among the authors, and using hand-written memos to portray the prospective relationships between the categories. During this analysis, we became convinced that one category (i.e., trialing behavior) was a central one because it was related to all other categories. Thus, it stood out from the other categories, and, accordingly, we emphasized it in our emerging model. The remaining 11 categories concerned issues that influenced both trialing behavior and switching behavior by either enabling or inhibiting them. For example, we found that low search and setup costs enable trialing behavior and switching behavior while stored personal data inhibits them. Finally, we bundled these categories by using descriptive terms to help readers easily read them: the issues related to current applications, application providers, application marketplace for alternatives, and lock-in.

Finally, we assessed our analysis by going through our data and comparing it with the emerging model (Berg, 2004). With this procedure, we focused on ensuring that the model covered all the aspects that the data suggested was important. At this point, we made only small refinements to the category names. As for triangulation, the main categories were recurrent across data sets and were mentioned by multiple users (Berg, 2004). In practice, we used NVivo to examine the data sets separately and ensured that each of the twelve categories contained coding references to at least two different data sets. Additionally, at least six participants mentioned each category. These practices support our conclusions that each identified issue was essentially influential to mobile users' switching behavior. We finalized the iterative collection and analysis when we obtained sufficient interpretations about the categories as issues that affect mobile application switching. Figure 1 summarizes our research process with coding examples.

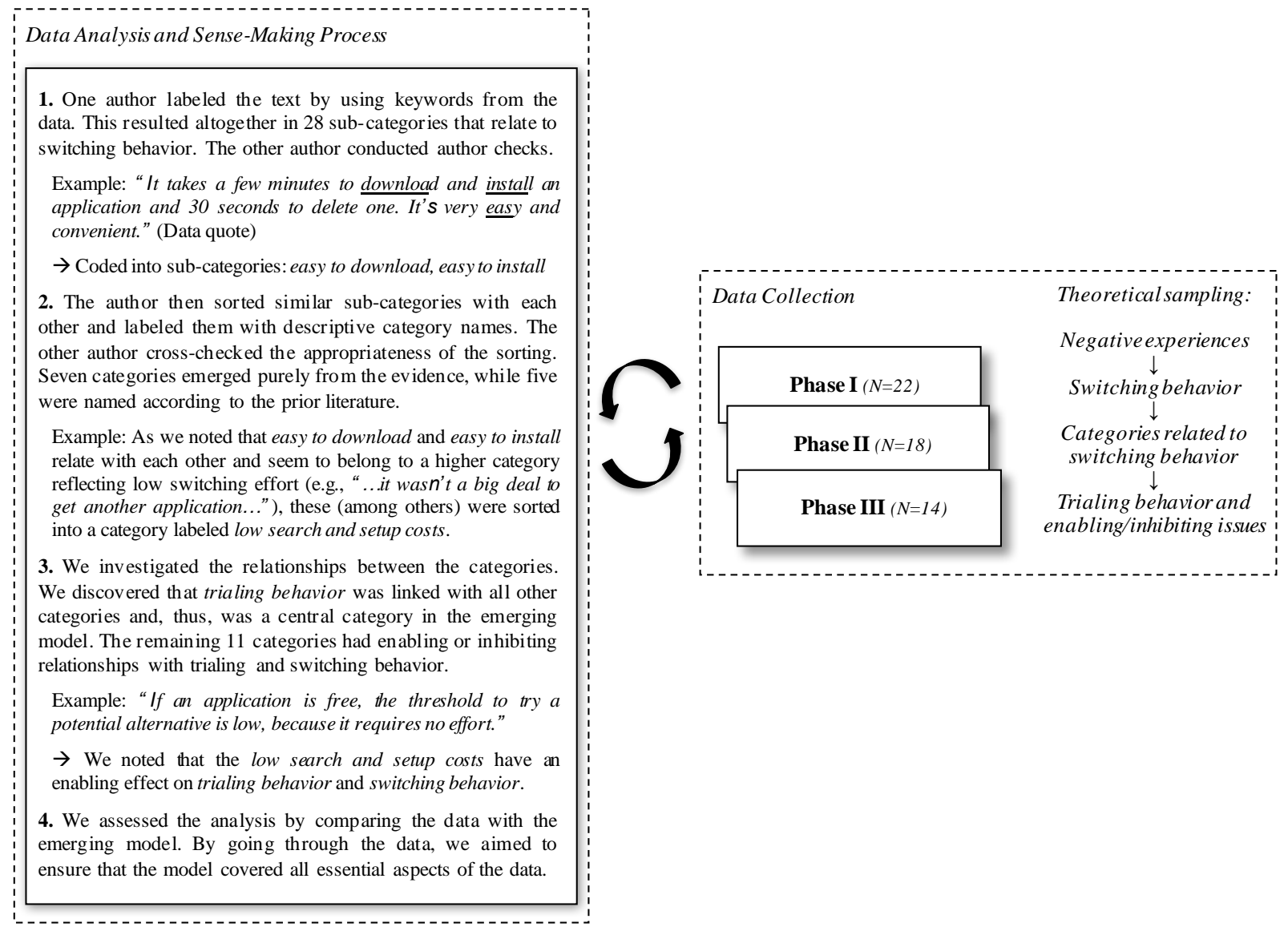

Figure 1. Illustration of the Research Process 


\section{Results}

Our resulting model (see Figure 2) summarizes our results. Based on our data, trialing behavior is a central predecessor of switching behavior. Further, we found 11 issues that affect mobile application users' trialing and switching behavior. Seven of the issues have an enabling effect on trialing and switching, while four issues have an inhibiting effect. We describe the model and its content in more detail as follows with translated quotations from the users.

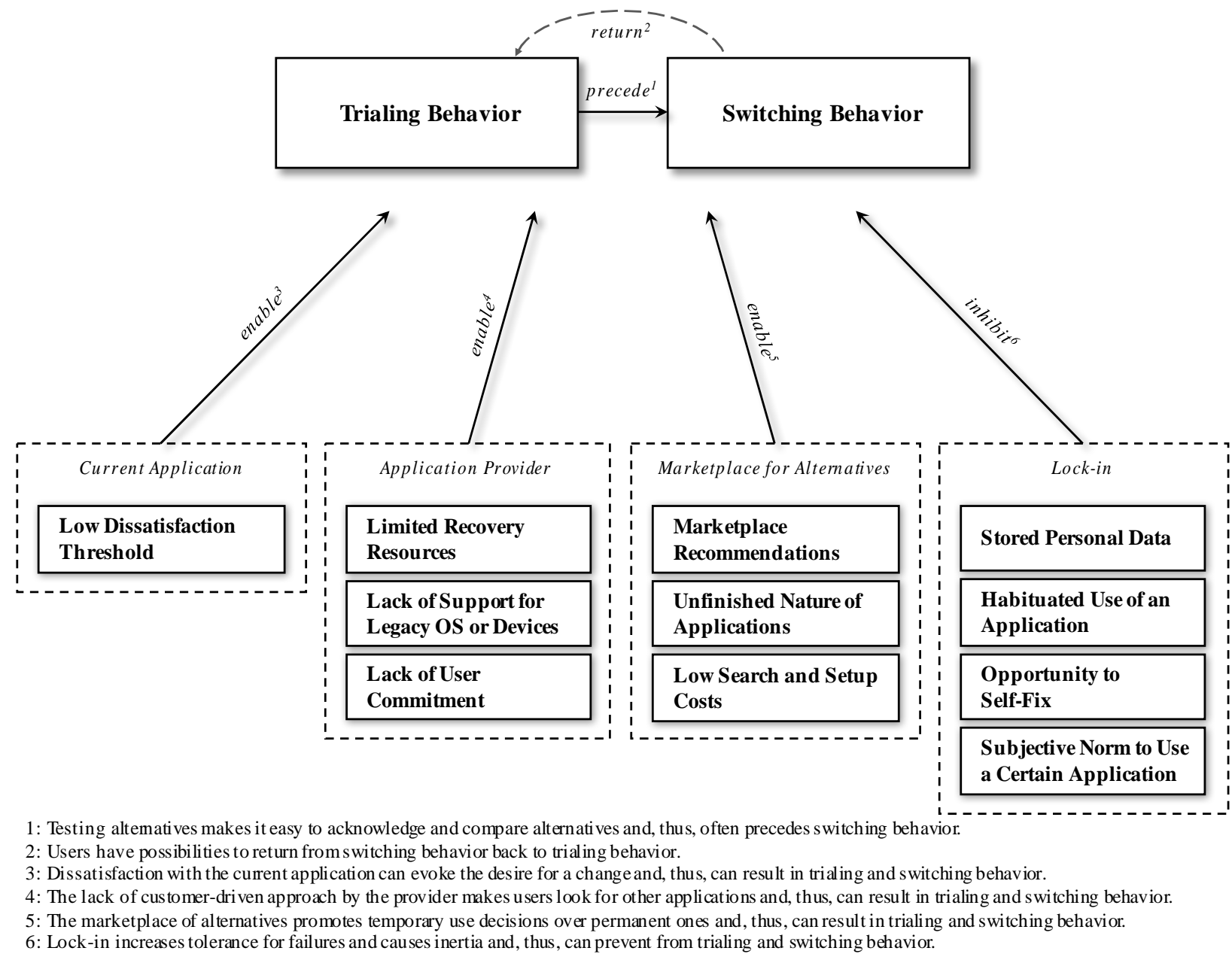

Figure 2. The Resulting Model on Mobile Application Users' Switching Behavior (User Perceptions)²

\subsection{Trialing Behavior}

According to our informants' switching experiences, a recurrent and separate type of behavior often occurs before they engage in switching behavior: trialing behavior. Based on our data, we define trialing behavior in the mobile application context as the testing of a mobile application in order to learn about the application and its characteristics without any actual commitment to switch. This refers to a separate period that occurs independently and, thus, is not yet switching behavior. Thus, trialing behavior appears to precede switching behavior.

The users perceived trialing behavior as a central determinant as to whether they switched mobile applications since it enabled them to try out the potential applications that they could consider as alternatives for their currently used applications. Indeed, our findings suggest that mobile application users

\footnotetext{
${ }^{2}$ Users may engage in switching-like behaviors such as using several similar applications simultaneously and "hopping" between them (e.g., using WhatsApp for some contacts, Facebook for others, and Skype for the rest). However, as the users often remain using also their original application, we did not consider such simultaneous use in our model.
} 
exhibit a culture of having trialing sessions and testing several applications before conducting an actual switch. They consider trialing mobile applications as a common and convenient due to the characteristics specific to the context of mobile applications (e.g., numerous alike alternative applications, access to applications with minimal effort, and reviews in the marketplaces). For example, one respondent mentioned that he switched applications after a "bustle that is all about swift trialing of the various applications' free versions".

On a more specific level, users may try out multiple alternative applications simultaneously or consecutively, compare them, cut down the list of alternatives one by one, and finally end up with the most suitable application. According to our data, the prospect list may include anything from two to 15 applications. As the following quotation illustrates, some conduct trials in a rather lightweight manner: "the testing often takes place at the workplace's toilet." In contrast, others conduct more extended trials by considering a bunch of applications in a "playoff spirit":

Interviewer: So, do you have some sort of a trial period [for the alternative applications]?

Respondent: Yes, as a matter of fact. With this [smartphone] I had three applications for calling. I was like what would be the most natural for me to use. I abandoned one [application] after one day, because it didn't have everything I needed, and now I'm trialing two other applications for the second week.

The previous example also illustrates that the users hold on for some time to the original application. Even after making the actual switch, they may not uninstall the original application, which increases the likelihood that they will return to using it if the new alternative fails to satisfy them:

I make the switching decision only after trialing an application. So I don't uninstall the original application from my smartphone immediately. This is actually why there are many unnecessary applications in my smartphone that are not in use, because I don't remember to remove the ones I don't use anymore.

As the previous examples illustrate, users may continue to trial other alternative applications after switching. Based on our data, such two-way interrelation between trialing and switching behavior appears to characterize the context of mobile applications.

\subsection{Issues Influencing Trialing Behavior and Switching Behavior}

\subsubsection{Low Dissatisfaction Threshold}

Dissatisfaction is one of the main triggers that enable switching behavior. When a user is dissatisfied with an application, they often begin to think about switching to an alternative. In the mobile application context, users appear to experience dissatisfaction relatively easily. For instance, the participants described how they became quite swiftly frustrated in situations such as having an application momentarily stuck in a loading screen, witnessing the inability of an application to immediately fetch a GPS signal, or experiencing a sporadic crash. With many mobile applications, users recognize the availability of alternatives and, thus, can quite harshly leave dissatisfying applications on the spur of the moment. As one participant said: "If it dissatisfies then I just get rid of it. I can always find another one!". The reasons for dissatisfaction vary and are often application specific (e.g., the user interface, visual appeal, logic of an application, complexity, bugs and errors, and security and privacy risks).

\subsubsection{Limited Recovery Resources}

Limited recovery resources refer to application providers' assets and abilities to respond to users' negative experiences. When it comes to mobile application providers, many respondents did not believe they could fix their issues via complaining; for example, one respondent said: "[I have] the feeling that complaining would end up being useless". Those users who think that they cannot make a difference by complaining tend to choose switching over other actions. These pessimistic expectations hold in the mobile application context in particular because users suppose that application providers have not allocated adequate resources to fix their issues or offer other forms of service recovery. We also found that users had stronger pessimistic expectations with popular applications or applications of large-sized or foreign providers. With that said, users did sometimes make the necessary effort to complain and seek help to fix their issues. However, as one participant indicated, they sometimes received no reply or inadequate help: 
"Some people [I know] have switched to an alternative application because they have given feedback about an issue but it hasn't been fixed".

\subsubsection{Lack of Support for Legacy OS or Devices}

Users may also switch applications due to a lack of update support from the application provider. Our data indicates that some applications' newer versions simply stop working with an older version of an operating system (OS) or that only users who have a device with an updated OS version may obtain them. In the mobile application context, applications commonly become outdated due to the rapid update cycles of mobile applications, OS versions, and devices. Sometimes, the device itself restricts users from using certain application features (e.g., near-field communication functions with mobile payment applications). The device also indirectly influences the availability of OS versions because smartphone providers often restrict their newest $\mathrm{OS}$ from functioning with older smartphones. The following example demonstrates such thoughts:

So, when any problems occur, I think immediately that it is just because my smartphone is too old, that I should buy a new to get the application working. And this has indeed happened many times. The old applications can't be updated and the new versions don't work with the old platform.

We can divide the dilemma further into two dimensions: users either cannot or do not want to upgrade their operating system or device. The first dimension concerns investing money or know-how into the new upgrades, and the second one concerns staying independent or being lazy.

\subsubsection{Lack of User Commitment}

Switching behavior occurs also due to the lack of user commitment: that is, users perceive that they have a weak relationship with application providers. As such, they perceive applications as rather generic, rarely have any relationship with providers, and view providers as "kind of faceless". According to the data, the simultaneous involvement of the application marketplace, application provider, and application developer blurs users' ability to interact with the actual people behind the application. As one respondent said:

When I buy or download an application for free, the relationship with the developer or developers is very thin and fuzzy. My experience is that I buy an application rather from [the marketplace] than from a single developer. [The marketplace] does not make it easy at all to build interaction between the developer and the customer.

With such a faceless relationship that involves no provider-user or developer-user interaction, users customarily do not feel responsible to providers or developers for their use behaviors. Therefore, because of the lacking commitment, users may feel that nobody will be disappointed or might not even notice if they switch to an alternative application.

\subsubsection{Application Marketplace Recommendations}

Application marketplaces often promote trialing and switching behavior because they efficiently recommend alternative applications according to users' interests. Indeed, users feel that the marketplaces' search and listing functions offer a great centralized foundation for comparing alternatives. We found that the typical process seems to proceed as follows:

When I go to the marketplace, it shows me a list of similar [applications], and I glance through the list. When I recognize something familiar, one that I've heard of, it's easy to select that one.

Even though users may have been using an application for a certain purpose, they often return to the marketplace to confirm or disconfirm their previous decision(s). The user feedback in the form of reviews and ratings steers the selection as one respondent said: "When [the ratings] are better on an average [for an alternative] than for my currently used application, l'll probably switch.".

\subsubsection{Unfinished Nature of Applications}

Unfinished nature of applications refers to the users' perception that mobile applications are not permanent and 100 percent ready. As opposed to many other products and services, users consider mobile applications as raw and underdeveloped "versions" that their developers may or may not enhance with, for instance, new features. Thus, users' uncertainty and suspicion about the future of the applications 
in question can drive them to consider trialing and switching rather than to wait for favorable updates that may never come about. This consideration results in a much looser attitude towards switching than with other products and services: unfinished applications can be neat to use for a moment but easy to ditch later on. According to our data, users portrayed application providers as commonly hurrying their unfinished works to the market; for instance, one respondent said: "The applications with a lot of competing [alternatives] have to be rushed onto the markets as raw versions and beta-tested on the fly in the early stage". For example, even though a mobile application may have a finalized website-based counterpart, many users do not expect the mobile application to be polished.

\subsubsection{Low Search and Setup Costs}

Mobile applications often come with remarkably low switching costs since, as one respondent said, "it is easier and cheaper to start using [new] mobile applications than nearly any other products". Indeed, many users confirmed that, because of the standardized application marketplaces, they perceived applications as cheap (or free) and that searching for and installing applications required only minimal effort. For example, one user stated that "it takes a few minutes to download and install an application and 30 seconds to uninstall one". Such low sacrifices and effort form a key explanation as to why dissatisfied users tend to choose trialing and switching behavior over coping with the problems or complaining about them to the application provider. As one respondent said: "I haven't bothered [to complain] but rather voted with my feet".

\subsubsection{Stored Personal Data}

According to our data, certain issues create lock-in and, thus, inhibit switching behavior. One issue is personal information logs that the user can store manually or that the application can store automatically. The mobile context offers special opportunities for logs because mobile devices are usually in personal use, users tend to carry their devices with them throughout the day, and applications can continue to run in the background and store data. Applications can restrict the data they store so that users cannot utilize it with other applications. For example, sports-tracking applications collect users' physical activity data that users cannot always export to other applications. As the following quotation illustrates, logged use history will encourage users to cope with the application and, thus, inhibit them from switching to a certain point.

When I have my own data [stored in the application], it's much more [unlikely] that I [will] switch. ...It makes me more committed to the application compared to the alternatives. Then I give it more priority.

However, if the source of dissatisfaction does not vanish, users will ultimately switch despite their use history logs:

On the other hand, when it comes to a [major] situation, well, I don't monitor my history [logs] too actively, so, it's not the most influential factor. When [the application] appears to lag all the time, then yes, [l switch].

\subsubsection{Habituated Use of an Application}

Referred to as a user's predetermined choice of preference for a certain application, the habit to use an application and previous experience with it can inhibit users from switching to unknown alternatives. In the mobile application context, habit formation can be relatively quick when users engage with their mobile applications frequently (e.g., numerous times a day). At times, users may not like to learn new applications as one responded said: "One inhibitor [to switch] is the learning barrier". For example, with a news application, users would have to learn and personalize the competing alternative applications to show the content they want to consume. However, we found that our respondents had different personal attitudes on this issue. While some users are eager to search, trial, learn, and switch applications, others remain in their comfort zone with familiar applications and the way they use them. Because of the latter attitude, a person might stick with a mediocre application in order to avoid switching as one respondent said:

At times I just don't want to switch because of habit, even though I knew the alternative application might have better features. Maybe getting familiar with a new application is not interesting enough for me, so that l'd chase the best ones, and therefore, I use those applications that I've already chosen by chance. 


\subsubsection{Opportunity to Self-fix}

Opportunity to self-fix refers to a user's opportunities to solve application problems on their own. Some users are persistent in fixing failures on their own as a prior option before they consider switching. As one respondent said: "I guess I'm that much stubborn that I have to beat my head against a stone wall once more, after my first attempt [to solve it]". We found that many users engage in such self-fixing persistence when they deal with IT and that this behavior roots back to their prior IT experiences. Users seem to accept that IT comes with failures and, thus, are used to inspecting problems, searching for information, and trying out potential solutions, such as changing the usage condition and booting the system. In the mobile context, there are relatively quick self-fix techniques such as applying flight mode or changing the Internet connection from Wi-Fi to a cellular network. Self-fix activities can be rewarding because they can result in sense of achievement. A few users admitted that the enjoyment of the challenge motivated them; for example, one respondent said:

Respondent: A careful detection of what might have went wrong.

Interviewer: Why do you, by the way, wish to do that?

Respondent: My curiosity, if I could [fix] it on my own.

Interviewer: Challenge?

Respondent: Exactly. Yes, [the prospective outcome]: I managed to solve it!

\subsubsection{Subjective Norm to Use a Certain Application}

The perceived normative pressure of users' social circles may prevent them from switching to an alternative. Especially in applications with communication features, the value of the application emerges through one's contacts. The mobile application context emphasizes as much given that applications are designed for communication: for example, almost all interviewees considered mobile applications as a major way to communicate and manage their social relations. Thus, social pressure inhibits users from switching due to the fear of losing social capital and being left out of something. Also, conflicts appear: users may simultaneously be dissatisfied with an application but want to use it because of their contacts. For instance, one user was disappointed when his version of an instant messaging application lacked a feature that previously had enabled him to differentiate his contacts with colors. As a result, he had difficulties in managing his numerous contacts. However, he could not switch applications because the particular application was the main way that he kept in touch with his social circle.

\section{Discussion}

In this study, we examine the previously unanswered question: why do users switch mobile applications? Our findings and model we developed advance research by explaining a highly frequent phenomenon that characterizes the use of mobile applications (e.g., Mashable, 2014). Thus, the findings can also help mobile application providers and developers in maintaining customer relationships and reducing user churn by widening their focus to issues that they may have previously ignored.

As our main theoretical contribution, we discovered that trialing behavior is a central predecessor of switching behavior due to the aspects specific for the mobile application context. This finding introduces a new perspective for IT switching: during users' trialing behavior, providers of the original applications may still have time and opportunities to retain their users before losing them entirely to competitors. Providers have such time and opportunities with users who are exploring their options but have yet to decide whether to switch or not (note that some applications use a technical trialing period, which is necessary even if a user has already made a switching decision). On the other hand, the discovery of trialing behavior opens possibilities for the competing application providers to acquire new users that are already prone to switching.

In addition, we uncovered 11 context-specific issues that either enable or inhibit trialing and switching behavior in the mobile application context. We estimate that all the issues of the model will be relevant with many common mobile application types, such as applications related to social networking, sports, news, commerce, entertainment, and games. However, some of the issues presented in our model may be more critical with certain mobile application types than with others. For instance, self-tracking applications or applications with social features tend to create more lock-in, which may constitute a relatively strong inhibitor of switching and overrule even a larger set of enabling issues. Therefore, 
researchers should evaluate the relative criticality of each issue of the model regarding the mobile application type of their interest.

\subsection{Theoretical Implications}

In Table 1, we summarize the position of our resulting model in relation to previous studies and present context-specific characteristics and interpretations of mobile application switching. To the best of our best knowledge, previously studies on IT switching have not presented trialing behavior and six of the 11 influencing issues. We focus on discussing these novel findings as follows.

First, mobile application usage is characterized by trialing behavior in which users test many alternatives in order to find their favorite. Importantly, our distinction between switching and trialing behavior enables researchers to take these two different behaviors into account when examining users' post-adoption behaviors. Acknowledging both trialing and switching behavior improves our understanding of the ways that users end up consuming particular applications: researchers have not included any aspects regarding trialing behavior in their previous theories and models on IT switching. We argue that researchers should acknowledge the existence of trialing behavior because it constitutes an important predecessor of switching behavior in the context of mobile applications and potentially also with other similar free or lowcost software. In contrast, trialing behavior is not as frequent when users consider switching IT hardware that, in many cases, users cannot test in real-life settings for free.

Second, our findings reveal insights regarding the role of application providers. When dissatisfied, users believe that application providers do not care about or have the resources for alleviating their issues. While IT switching studies have ignored the influence of the recovery resources issue, the service literature has discussed it in the switching behavior context (e.g., Keaveney, 1995). We strongly suggest that IS researchers consider what affect that such recovery resource issues have on mobile application and IT switching. Additionally, the rapid update cycles reflect dilemmas for mobile application providers: users do appreciate the constantly updating application features but may become disappointed if the updates render their OS and devices obsolete. Hence, OS and device support seems to have a multifaceted effect on switching behavior in the mobile application context.

Third, as mobile users are accustomed to the abundance of similar alternative applications in the marketplace, they are almost born to switch. Even though users may find their favorite applications for a period of time, their mindset rarely includes continuing with the same application forever. Although this assertion can hold true also with some other types of software, researchers should take these characteristics into special consideration when looking at mobile application switching. Recommendations also are highly impactful in the mobile application context, where application marketplaces' offer easy comparisons of numerous alternatives through a huge number of user-generated reviews. Much research on online reviews, which has concluded that online recommendations can enable switching, supports our findings (e.g., Li, Hitt, \& Zhang, 2011).

Fourth, the barriers to switch to an alternative rise when users have, for instance, documented their reallife experiences into an application. To our best knowledge, research has not previously presented stored personal data as an issue that influences switching behavior. However, literature about personalization does contain closely related results that support our findings: for instance, research has found that investments in website profiles, interactive activities, and personal identity promote lock-in (Kim \& Son 2009; Park, 2014). Thus, we believe that stored personal data is influential also in many other IT switching contexts, such as software and hardware-software bundles. Another inhibitor of mobile application switching is users' opportunities to fix their application problems on their own. As a concept, we deem that the opportunity to self-fix can be an important issue in various IT switching contexts, including both software and devices.

Finally, our results do not feature some drivers of IT switching that previous studies have mentioned. For example, we focused on more concrete issues rather than on users' emotional reactions (Chang et al., 2014; Dang et al., 2015), although we acknowledge that they may have a role behind the issues that we found. As another example, our data did not highlight security issues to directly enable or inhibit switching as presented in prior studies (Ye \& Potter, 2011; Ye et al., 2008). We found out that poor security could be an antecedent of dissatisfaction, but we believe that researchers may need to emphasize the role of security in the future. 
Table 1. Issues Compared to Prior Studies on IT Switching

\begin{tabular}{|c|c|c|}
\hline $\begin{array}{l}\text { Category in our } \\
\text { model }\end{array}$ & $\begin{array}{l}\text { New category / } \\
\text { category in } \\
\text { literature }\end{array}$ & $\begin{array}{l}\text { Characteristics of the mobile application context and related } \\
\text { interpretations }\end{array}$ \\
\hline Trialing behavior & New & $\begin{array}{l}\text { The culture of trialing several alternatives simultaneously: users engage } \\
\text { in trialing behavior more often with mobile applications than with other } \\
\text { types of IT }\end{array}$ \\
\hline \multicolumn{3}{|l|}{ Influencing issues } \\
\hline $\begin{array}{l}\text { Low dissatisfaction } \\
\text { threshold }\end{array}$ & $\begin{array}{l}\text { (Dis) satisfaction } \\
(1-4,6-8,11,13 \\
15-18,20-23,25- \\
28)\end{array}$ & $\begin{array}{l}\text { Dissatisfaction may immediately lead to the trialing of alternatives: users } \\
\text { admit they have less patience with mobile applications than with other } \\
\text { types of IT }\end{array}$ \\
\hline $\begin{array}{l}\text { Limited recovery } \\
\text { resources }\end{array}$ & New & $\begin{array}{l}\text { The lack of belief in application providers' interest for individual users: } \\
\text { users perceive that many application providers have less resources (per } \\
\text { user) for recovery options than the providers of many other types of IT }\end{array}$ \\
\hline $\begin{array}{l}\text { Lack of support for } \\
\text { legacy OS or devices }\end{array}$ & New & $\begin{array}{l}\text { Rapid update cycles may force users to switch: mobile devices and } \\
\text { applications are updated more often than many other types of IT and, } \\
\text { thus, can become outdated faster }\end{array}$ \\
\hline $\begin{array}{l}\text { Lack of user } \\
\text { commitment }\end{array}$ & Commitment (15) & $\begin{array}{l}\text { Applications are perceived generic and standardized: users feel less } \\
\text { guilty about ditching mobile applications compared to many other types of } \\
\text { IT }\end{array}$ \\
\hline $\begin{array}{l}\text { Application } \\
\text { marketplace } \\
\text { recommendations }\end{array}$ & New & $\begin{array}{l}\text { Marketplaces' search listings reduce search costs and reviews enable } \\
\text { comparison: users perceive that the marketplace reviews and top lists are } \\
\text { more centralized than the ones of many other types of IT }\end{array}$ \\
\hline $\begin{array}{l}\text { Unfinished nature of } \\
\text { applications }\end{array}$ & New & $\begin{array}{l}\text { Applications are perceived as constantly evolving and temporary: users } \\
\text { expect mobile applications to be less perfect and permanent than many } \\
\text { other types of IT }\end{array}$ \\
\hline $\begin{array}{l}\text { Low search and setup } \\
\text { costs }\end{array}$ & \begin{tabular}{|c} 
Switching costs \\
including setup \\
costs $(1,3,5,6-8$, \\
$\begin{array}{c}11,13,14,16,18 \\
19,21,23-25,27- \\
29)\end{array}$ \\
\end{tabular} & $\begin{array}{l}\text { Alternatives are easy and cheap to search, install, and get rid of: } \\
\text { searching and setting up mobile applications is perceived faster and } \\
\text { simpler than many other types of IT }\end{array}$ \\
\hline Stored personal data & New & $\begin{array}{l}\text { Stored personal data increases coping efforts: personal mobile devices } \\
\text { and their applications are suitable for collecting user data (e.g., 24/7 self- } \\
\text { tracking) and creating lock-in }\end{array}$ \\
\hline $\begin{array}{l}\text { Habituated use of an } \\
\text { application }\end{array}$ & Habit $(2,19,25)$ & $\begin{array}{l}\text { Developing a habit and settling for an application to avoid learning efforts: } \\
\text { users often engage in more instances of use (e.g., per day) with mobile } \\
\text { applications than with other types of IT and, thus, can become quickly } \\
\text { habituated to use their existing applications }\end{array}$ \\
\hline Opportunity to self-fix & New & $\begin{array}{l}\text { Routinized mindset to fix applications by oneself, enjoyment of the } \\
\text { challenge: common and quick techniques (e.g., apply flight-mode or } \\
\text { change network connection) make self-fixing more realizable with mobile } \\
\text { applications than with many other types of IT }\end{array}$ \\
\hline $\begin{array}{l}\text { Subjective norm to use } \\
\text { a certain application }\end{array}$ & $\begin{array}{l}\text { Subjective norm } \\
(1,19,22,24,25 \\
28)\end{array}$ & $\begin{array}{l}\text { Rejecting alternatives because of social utility and pressure: users } \\
\text { manage their social relations more via mobile applications than with other } \\
\text { IT }\end{array}$ \\
\hline \multicolumn{3}{|c|}{ 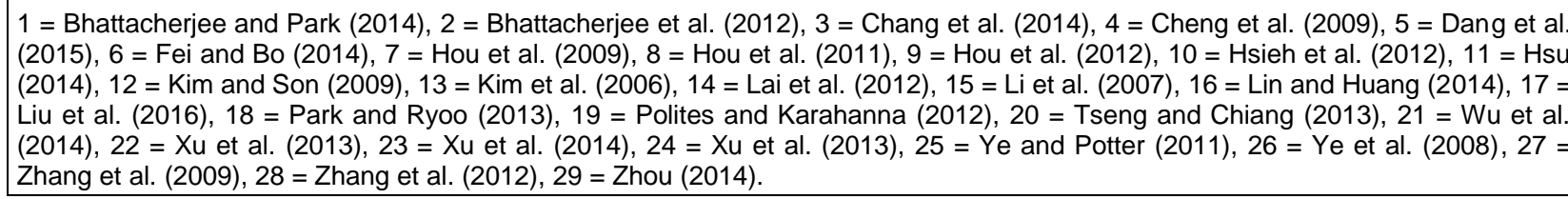 } \\
\hline
\end{tabular}




\subsection{Practical Implications}

In terms of practice, our identification of trialing behavior as a separate phase that typically precedes the switching behavior related to mobile applications offers application providers and developers important implications. If an application provider can (ethically) notice that users are trialing with different application alternatives (e.g., by surveying users whose usage time or login counts have substantially decreased), they can interpret such signs as a warning that they may switch from one application to another in the near future if they can find an alternative that they perceive to be better than the original application. In such cases, it also offers application providers one last chance to intervene in the situation through measures that promote the attractiveness of the current application or undermine that of the alternatives in order to prevent the switch from ever taking place. Such measures could include, for example, temporary or permanent reductions in the in-app purchase charges of the current application or the addition of some alluring extra features on a temporary or permanent basis.

Second, application providers and developers could offer better support for users' issues. For example, application providers should emphasize in their communication that they take user feedback seriously, offer easy feedback forms, and use log data to locate suitable intervention moments for "Have you had a problem with our app? Let us help" type of messages. By using such techniques to convince users, application providers can efficiently both show service quality and shorten the list of switching enablers.

Third, we recommend application providers and developers to avoid unnecessarily restricting their applications from operating on older OS versions and devices. Even though application providers and developers themselves often use novel technology with frequent updates, it should be kept in mind that average mobile application users typically use a wide variety of OS versions and devices.

Fourth, application providers and developers would also benefit from taking advantage of users' potential persistence to fix their problems themselves. One way they could do so would involve figuring out popular search words for the application-related problems and then supporting the enthusiastic users by offering search engine-optimized manuals and guides or a community platform to discuss them.

Finally, the inhibiting effects of stored data and habituated use on switching behavior offer multiple possibilities. Application providers could aim for lock-in by allowing users to record their own data and personalize the applications. Additionally, they could develop sophisticated techniques by which users could teach the applications their habits and preferences. Such habitual and experience-based issues can make users even more committed to the applications and, hence, inhibit them from switching to alternatives.

\subsection{Limitations and Future Topics}

This study has several limitations. First, we focused on finding diverse explanations for switching behavior rather than achieving full generalizability. In particular, one could consider the amount of interviewees (18) and total participants (54) a limitation: we caution readers when interpreting our findings and generalizing them across other IT contexts. We conclude that all detailed findings of this study are not fully generalizable but that researchers can apply the model and its concepts when examining the switching of mobile applications and other similar software (e.g., smart watch applications). Second, we did not dive deep into the different types of applications. We mentioned some examples of the application types specific to certain enabling or inhibiting issues, but it would be interesting to conduct further comparisons regarding different application types. Third, future studies could potentially use our findings to explore the more detailed nuances of the mobile application ecosystem. For example, users may engage in switchinglike behaviors such as simultaneously using several similar applications and/or hopping between them. Further, some applications may have mandatory trialing periods, and there might be differences in switching behavior regarding different operating systems (e.g., iOS vs. Android). Fourth, issues that influence human behavior can be difficult (if not impossible) to classify into exclusive categories with no overlap or interrelations with each other. Thus, interrelations and some overlap may exist. For example, future studies could examine the detailed interrelations and dynamics between trialing and switching behavior. Fifth, we assumed that application switching is negative from the perspective of individual application providers. However, individual users and the overall market itself may benefit from switching behavior. Finally, the study involved only Finnish mobile users. Thus, our findings may emphasize some characteristics of a certain nationality and culture. However, we estimate that the main findings and issues uncovered in our study also apply to other developed countries where users can employ contemporary mobile devices, access application marketplaces with numerous applications, have basic skills of using 
their mobile devices and applications, and have the freedom to choose which applications they wish to use. In the future, researchers could also examine whether there are cultural differences in IT switching behavior.

\section{Conclusions}

As mobile application providers commonly lose users to competitors, we need to understand why users switch mobile applications. Prior IT switching studies have not examined the unique context of mobile applications, which differs from many other IT products and services because of the highlighted role of alternatives, beta versions, update cycles, reviews, and users' spontaneous behavior. Therefore, we present a context-specific model of mobile application switching. Importantly, we found that trialing behavior is an essential predecessor of switching behavior: during trialing behavior, application providers may still retain their users before losing them entirely. Our findings also uncovered six novel issues that influence mobile application switching. With the help of our findings, researchers can apply these newly found issues in their future models. These findings can also assist mobile application providers to reduce user churn in the overcrowded, dynamic, and hypercompetitive mobile application market. 


\section{References}

Anckar, B., \& D'Incau, D. (2002). Value creation in mobile commerce: Findings from a consumer survey. Journal of Information Technology Theory and Application, 4(1), 43-64.

Bansal, H. S., Taylor, S. F., \& James, Y. S. (2005). "Migrating" to new service providers: Toward a unifying framework of consumers' switching behaviors. Journal of the Academy of Marketing Science, 33(1), 96-115.

Berg, B. L. (2004). Qualitative research methods for the social sciences. Boston, MA: Pearson Education.

Bhattacherjee, A. (2001). Understanding information systems continuance: An expectation-confirmation model. MIS Quarterly, 25(3), 351-370.

Bhattacherjee, A., Limayem, M., \& Cheung, C. M. K. (2012). User switching of information technology: A theoretical synthesis and empirical test. Information \& Management, 49(7-8), 327-333.

Bhattacherjee, A., \& Park, S. C. (2014). Why end-users move to the cloud: A migration-theoretic analysis. European Journal of Information Systems, 23(3), 357-372.

Bogue, D. J. (1969). Principles of demography. New York: John Wiley.

Chandra, S., Srivastava, S. C., \& Theng, Y.-L. (2010). Evaluating the role of trust in consumer adoption of mobile payment systems: An empirical analysis. Communications of the Association for Information Systems, 27, 561-588.

Chang, I., Liu, C., \& Chen, K. (2014). The push, pull and mooring effects in virtual migration for social networking sites. Information Systems Journal, 24(4), 323-346.

Cheng, Z., C., Yang, Y., \& Lim, J. (2009). Cyber migration: An empirical investigation on factors that affect users' switch intentions in social networking sites. In Proceedings of the 42nd Hawaii International Conference on System Sciences.

CNet. (2015). YouTube app no longer supports older TVs, outdated iOS devices. Retrieved from http://www.cnet.com/news/youtube-app-to-no-longer-support-older-tvs-or-ios-devices/

Dang, Y. M., Zhang, Y. G., \& Morgan, J. (2015). Integrating switching costs to information systems adoption: An empirical study on learning management systems. Information Systems Frontiers, 120.

Davis, F. D. (1989). Perceived Usefulness, perceived ease of use, and user acceptance of information technology. MIS Quarterly, 13(3), 319-339.

DeLone, W. H., \& McLean, E. R. (2003). The DeLone and McLean model of information systems success: A ten-year update. Journal of Management Information Systems, 19(4), 9-30.

Fei, L., \& Bo, X. (2014). Do I switch? Understanding users' intention to switch between social network sites. In Proceedings of the 47th Hawaii International Conference on System Sciences.

Glaser, B. G., \& Strauss, A. L. (1967). The discovery of grounded theory: Strategies for qualitative research. New Brunswich: AldineTransaction.

Grover, V. (2014). Value of IS research: Let's not talk crisis-but we can do better. Communications of the Association for Information Systems, 34, 837-842.

Grover, V., \& Lyytinen, K. (2015). New state of play in information systems research: The push to the edges. MIS Quarterly, 39(2), 271-296.

Hou, A. C., Chen, Y., Shang, R., \& Chern, C. (2012). The post adoption switching of social network service: A human migratory model. In Proceedings of the Pacific Asia Conference on Information Systems.

Hou, A. C. Y., Chern, C.-C., Chen, H.-G., \& Chen, Y.-C. (2009). Using demographic migration theory to explore why people switch between online games. In Proceedings of the 42nd Hawaii International Conference on System Sciences. 
Hou, A. C., Chern, C., Chen, H., \& Chen, Y. (2011). "Migrating to a new virtual world": Exploring MMORPG switching through human migration theory. Computers in Human Behavior, 27(5), 18921903.

Hsieh, J.-K., Hsieh, Y.-C., Chiu H.-C., \& Feng, Y.-C. (2012). Post-adoption switching behavior for online service substitutes: A perspective of the push-pull-mooring framework. Computers in Human Behavior, 28(5), 1912-1920.

Hsu, J. S. (2014). Understanding the role of satisfaction in the formation of perceived switching value. Decision Support Systems, 59, 152-162.

Keaveney, S. M. (1995). Customer switching behavior in service industries: An exploratory study. Journal of Marketing, 59(2), 71-82.

Kim, G., Shin, B., \& Lee, H. G. (2006). A Study of factors that affect user intentions toward email service switching. Information \& Management, 43(7), 884-893.

Kim, S. S., \& Son, J.-Y. (2009). Out of dedication or constraint? A dual model of post-adoption phenomena and its empirical test in the context of online services. MIS Quarterly, 33(1), 49-70.

Lai, J., Debbarma, S., \& Ulhas, K. R. (2012). An empirical study of consumer switching behaviour towards mobile shopping: A push-pull-mooring model. International Journal of Mobile Communications, 10(4), 386-404.

Lee, E. S. (1966). A theory of migration. Demography, 3, 47-57

Li, D., Browne, G. J., \& Wetherbe, J. C. (2007). Online consumers' switching behavior: A buyer-seller relationship perspective. Journal of Electronic Commerce in Organizations, 5(1), 30-42.

Li, X., Hitt, L. M., \& Zhang, Z. J. (2011). product reviews and competition in markets for repeat purchase products. Journal of Management Information Systems, 27(4), 9-41.

Liu, Y., Li, H., Xu, X. Kostakos, J., \& Heikkilä, J. (2016). Modeling consumer switching behavior in social network games by exploring consumer cognitive dissonance and change experience. Industrial Management \& Data Systems, 4, 801-820.

Lin, T., \& Huang, S. (2014). Understanding the determinants of consumers' switching intentions in a standards war. International Journal of Electronic Commerce, 19(1), 163-189.

Mashable. (2014). Millions flock to Telegram messaging app after WhatsApp outage. Retrieved September from http://mashable.com/2014/02/23/telegram/

Merali, Y., Papadopoulos, T., \& Nadkarni, T. (2012). Information systems strategy: Past, present, future? The Journal of Strategic Information Systems, 21(2), 125-153.

Myers, M. D., \& Newman, M. (2007). The qualitative interview in IS research: Examining the craft. Information and Organization, 17(1), 2-26.

Park, S. C., \& Ryoo, S. Y. (2013). An empirical investigation of end-users' switching toward cloud computing: A two factor theory perspective. Computers in Human Behavior, 29(1), 160-170.

Park, J.-H. (2014). The effects of personalization on user continuance in social networking sites. Information Processing and Management, 50(3), 462-475.

Patton, M. Q. (1990). Qualitative evaluation and research methods. Thousand Oaks, CA: Sage.

Polites, G. L., \& Karahanna, E. (2012). Shackled to the status quo: The inhibiting effects of incumbent system habit, switching costs, and inertia on new system acceptance. MIS Quarterly, 36(1), 21-42.

Rogers, E. M. (1995). Diffusion of innovations. New York: Free Press.

Shoemaker, S., \& Lewis, R. C. (1999). Customer loyalty: The future of hospitality marketing. International Journal of Hospitality Management, 18(4), 345-370.

Statista. (2016). Number of apps available in leading app stores as of June 2016. Retrieved from http://www.statista.com/statistics/276623/number-of-apps-available-in-leading-app-stores/

Tseng, F., \& Chiang, H. (2013). Exploring consumers to buy innovative products: Mobile phone upgrading intention. The Journal of High Technology Management Research, 24(2), 77-87. 
Urquhart, C., \& Fernández, W. (2013). Using grounded theory method in information systems: The researcher as blank slate and other myths. Journal of Information Technology, 28(3), 224-236.

van der Heijden, H. (2012). User acceptance of electronic commerce: Contributions from the Bled eConference. In Proceedings of the BLED eConference.

Venkatesh, V., Brown, S. A., \& Bala, H. (2013). Bridging the qualitative-quantitative divide: Guidelines for conducting mixed methods research in information systems. MIS Quarterly, 37(1), 21-54.

Venkatesh, V., Morris, M. G., Davis, G. B., \& Davis, F. D. (2003). User acceptance of information technology: Toward a unified view. MIS Quarterly, 27(3), 425-478.

Venkatesh, V., Thong, J. Y. L., \& Xu, X. (2012). Consumer acceptance and use of information technology: Extending the unified theory of acceptance and use of technology. MIS Quarterly, 36(1), 157-178.

Webster, J., \& Watson, R.T. (2002). Analyzing the past to prepare for the future: Writing a literature review. MIS Quarterly, 26(2), xiii-xxiii.

Wu, Y., Tao, Y., Li, C., Wang, S., \& Chiu, C. (2014). User-switching behavior in social network sites: A model perspective with drill-down analyses. Computers in Human Behavior, 33, 92-103.

Xu, X., Li, H., \& Heikkilä, J. (2013a). Understanding individuals' switching of eservice: An empirical study of social network games switching intentions in China. In J. Järveläine, H. Li, A. M. Tuikka, \& T. Kuusela (Eds.), Co-created effective, agile, and trusted eservices (LNBIP vol. 155, pp. 85-96). Berlin: Springer.

Xu, X., Li, H., Heikkilä, J., \& Liu, Y. (2013b). Exploring individuals' switching behaviour: An empirical investigation in social network games in China. In Proceedings of the 26th Bled eConference (pp. 141-153).

Xu, Y. C., Yang, Y., Cheng, Z., \& Lim, J. (2014). Retaining and attracting users in social networking services: An empirical investigation of cyber migration. The Journal of Strategic Information Systems, 23(3), 239-253.

Ye, C., \& Potter, R. (2011). The role of habit in post-adoption switching of personal information technologies: An empirical investigation. Communications of the Association for Information Systems, 35, 585-610.

Ye, C., Seo, D., Desouza, K. C., Sangareddy, S. P., \& Jha, S. (2008). Influences of IT substitutes and user experience on post-adoption user switching: An empirical investigation. Journal of the American Society for Information Science and Technology, 59(13), 2115-2132.

Zein, S., Salleh, N., \& Grundy, J. (2016). A systematic mapping study of mobile application testing techniques. Journal of Systems and Software, 117, 334-356.

Zhang, K. Z. K., Cheung, C. M. K., \& Lee, M. K. O. (2012). Online switching behavior: The case of blog service providers. Journal of Electronic Commerce Research, 13(3), 184-197.

Zhang, K. Z. K., Lee, M. K. O., Cheung, C. M. K., \& Chen, H. (2009). Understanding the role of gender in bloggers' switching behavior. Decision Support Systems, 47(4), 540-546.

Zhou, T. (2011). An empirical examination of users' post-adoption behaviour of mobile services. Behaviour \& Information Technology, 30(2), 241-250.

Zhou, T. (2014). Understanding users' switching from online stores to mobile stores. Information Development, 32(1), 60-69. 


\section{Appendix}

Table A1. Review of IT Switching Studies

\begin{tabular}{|c|c|c|c|}
\hline Study & $\begin{array}{c}\text { Switching } \\
\text { context }\end{array}$ & $\begin{array}{l}\text { Applied } \\
\text { theories }\end{array}$ & $\begin{array}{l}\text { Issues influencing switching behavior (brackets: non- } \\
\text { significant effect) }\end{array}$ \\
\hline $\begin{array}{l}\text { Ye et al. } \\
(2008)\end{array}$ & $\begin{array}{c}\text { Web } \\
\text { browsers }\end{array}$ & $\begin{array}{l}\text { Various } \\
\text { references }\end{array}$ & $\begin{array}{l}\text { - Influence of the current: satisfaction with current, breadth of use } \\
\text { - Moderating: user experience } \\
\text { - Influence of the alternative: relative advantage, ease of use, } \\
\text { security }\end{array}$ \\
\hline $\begin{array}{l}\text { Ye \& Potter } \\
\quad(2011)\end{array}$ & $\begin{array}{c}\text { Web } \\
\text { browsers }\end{array}$ & $\begin{array}{c}\text { Push-pull- } \\
\text { mooring (PPM) } \\
\text { framework and } \\
\text { other references } \\
\end{array}$ & $\begin{array}{l}\text { - Push of the current: satisfaction with the current } \\
\text { - Moore: switching cost, subjective norm, habit } \\
\text { - Pull of the alternative: relative advantage, relative ease of use, } \\
\text { relative security }\end{array}$ \\
\hline $\begin{array}{l}\text { Bhattacherjee } \\
\text { et al. (2012) }\end{array}$ & $\begin{array}{c}\text { Web } \\
\text { browsers }\end{array}$ & $\begin{array}{l}\text { Various } \\
\text { references }\end{array}$ & $\begin{array}{l}\text { - Satisfaction with the current } \\
\text { - Relative advantage of the alternative } \\
\text { - Habit } \\
\text { - Personal innovativeness }\end{array}$ \\
\hline $\begin{array}{l}\text { Kim \& Son } \\
\text { (2009) }\end{array}$ & Web portals & $\begin{array}{l}\text { Dual model of } \\
\text { relationship } \\
\text { maintenance }\end{array}$ & - Personalization \\
\hline $\begin{array}{l}\text { Li, Browne, \& } \\
\text { Wetherbe } \\
(2007)\end{array}$ & $\begin{array}{l}\text { Electronic } \\
\text { commerce } \\
\text { websites }\end{array}$ & $\begin{array}{l}\text { Buyer-seller } \\
\text { relationship }\end{array}$ & $\begin{array}{l}\text { - Commitment } \\
\text { - Trust } \\
\text { - Satisfaction } \\
\text { - Comparison of the alternatives } \\
\text { - Non-retrievable investment }\end{array}$ \\
\hline $\begin{array}{l}\text { Lai et al. } \\
\text { (2012) }\end{array}$ & \begin{tabular}{|c|}
$\begin{array}{c}\text { From desktop } \\
\text { to mobile } \\
\text { shopping }\end{array}$ \\
\end{tabular} & PPM & $\begin{array}{l}\text { - Push of the current: inconvenience } \\
\text { - Moore: high switching costs, low trust, low security and privacy } \\
\text { - Pull of the alternative: peer influence, alternative attractiveness }\end{array}$ \\
\hline Zhou (2014) & $\begin{array}{l}\text { Online to } \\
\text { mobile } \\
\text { shopping }\end{array}$ & $\begin{array}{l}\text { Various } \\
\text { references }\end{array}$ & $\begin{array}{l}\text { - Ubiquitous connection } \\
\text { - Trust transfer } \\
\text { - Contextual offering } \\
\text { - Flow } \\
\text { - Switching costs } \\
\text { - Switching barrier }\end{array}$ \\
\hline $\begin{array}{l}\text { Chang et al. } \\
\quad(2014)\end{array}$ & $\begin{array}{l}\text { Social } \\
\text { networking } \\
\text { sites }\end{array}$ & PPM & $\begin{array}{l}\text { - Push of the current: regret, dissatisfaction } \\
\text { - Moore: switching costs as sunk, setup and continuity cost } \\
\text { - Pull of the alternative: alternative attractiveness }\end{array}$ \\
\hline $\begin{array}{l}\text { Cheng, Yang, } \\
\& \text { Lim (2009) }\end{array}$ & $\begin{array}{l}\text { Social } \\
\text { networking } \\
\text { sites }\end{array}$ & PPM & $\begin{array}{l}\text { - Push of the current: dissatisfaction as member policy (technical } \\
\text { quality, information quality, community support) } \\
\text { - Moore: (switching costs as setup and continuity) } \\
\text { - Pull of the alternative: attraction as peer influence (and } \\
\text { attractiveness of alternatives) }\end{array}$ \\
\hline $\begin{array}{l}\text { Xu et al. } \\
(2014)\end{array}$ & $\begin{array}{l}\text { Social } \\
\text { networking } \\
\text { sites }\end{array}$ & PPM & $\begin{array}{l}\text { - Push of the current: dissatisfaction as entertainment, socialization } \\
\text { support, (technical quality, information quality, member policy) } \\
\text { - Moore: switching costs as continuity cost (setup cost) } \\
\text { - Pull of the alternative: attraction } \\
\text { - Peer influence }\end{array}$ \\
\hline $\begin{array}{l}\text { Hou, Chen, } \\
\text { Shang, \& } \\
\text { Chern (2012) }\end{array}$ & $\begin{array}{l}\text { Social } \\
\text { networking } \\
\text { sites }\end{array}$ & PPM & $\begin{array}{l}\text { - Push of the current: socializing level, entertainment levels, } \\
\text { (dissatisfaction with customer service) } \\
\text { - Pull of the alternative: attractiveness, peer influence, critical mass }\end{array}$ \\
\hline $\begin{array}{l}\text { Wu et al. } \\
(2014)\end{array}$ & $\begin{array}{l}\text { Social } \\
\text { networking } \\
\text { sites }\end{array}$ & $\begin{array}{l}\text { Various } \\
\text { references }\end{array}$ & $\begin{array}{l}\text { - Service quality: efficiency, availability, fulfillment, privacy, } \\
\text { compensation, contact, responsiveness } \\
\text { - Satisfaction } \\
\text { - Switching cost: risk, evaluation, learning, benefit loss, brand } \\
\text { relationship loss, personal relationship loss } \\
\text { - Switching barrier }\end{array}$ \\
\hline
\end{tabular}


Table A1. Review of IT Switching Studies

\begin{tabular}{|c|c|c|c|}
\hline $\begin{array}{l}\text { Fei \& Bo } \\
\text { (2014) }\end{array}$ & $\begin{array}{l}\text { Social } \\
\text { networking } \\
\text { sites }\end{array}$ & $\begin{array}{l}\text { PPM with uses } \\
\text { and gratification } \\
\text { theory }\end{array}$ & $\begin{array}{l}\text { - (Push of the current: dissatisfaction as information quality, } \\
\text { community support, membership policy and system quality) } \\
\text { - Moore: switching costs as sunk cost, pre-switching searching and } \\
\text { evaluation, post-switching behavioral and cognitive, uncertainty, } \\
\text { (setup and lost performance) } \\
\text { - Pull of the alternative: relative attractiveness as socialization value, } \\
\text { social image value, escapism value, self-improvement value, } \\
\text { (entertainment value and information seeking value) }\end{array}$ \\
\hline Hsu (2014) & $\begin{array}{l}\text { Mobile } \\
\text { devices }\end{array}$ & $\begin{array}{l}\text { Satisfaction and } \\
\text { value-based } \\
\text { decision model }\end{array}$ & $\begin{array}{l}\text { - Switching value } \\
\text { - Switching benefits } \\
\text { - Switching costs } \\
\text { - Satisfaction }\end{array}$ \\
\hline $\begin{array}{l}\text { Lin \& Huang } \\
\quad(2014)\end{array}$ & $\begin{array}{l}\text { Mobile } \\
\text { devices }\end{array}$ & PPM & $\begin{array}{l}\text { - Push of the current: disconfirmation, dissatisfaction } \\
\text { - Moore: inertia, switching cost, network effect, (subjective norm) } \\
\text { - Pull of the alternative: relative advantage }\end{array}$ \\
\hline $\begin{array}{c}\text { Tseng \& } \\
\text { Chiang (2013) }\end{array}$ & $\begin{array}{l}\text { Mobile } \\
\text { devices }\end{array}$ & $\begin{array}{l}\text { TAM, } \\
\text { expectation- } \\
\text { confirmation } \\
\text { model, and } \\
\text { other references }\end{array}$ & $\begin{array}{l}\text { - Price } \\
\text { - Enjoyment } \\
\text { - Usefulness } \\
\text { - Ease of use } \\
\text { - Satisfaction }\end{array}$ \\
\hline $\begin{array}{l}\text { Polites \& } \\
\text { Karahanna } \\
\text { (2012) }\end{array}$ & $\begin{array}{l}\text { Collaboration } \\
\text { tools }\end{array}$ & Status quo bias & $\begin{array}{l}\text { - Inertia } \\
\text { - Sunk costs } \\
\text { - Transitions costs } \\
\text { - Habit } \\
\text { - Ease of use } \\
\text { - Relative advantage } \\
\text { - Subjective norm }\end{array}$ \\
\hline $\begin{array}{l}\text { Dang et al. } \\
(2015)\end{array}$ & $\begin{array}{l}\text { Learning } \\
\text { systems }\end{array}$ & $\begin{array}{l}\text { Various } \\
\text { references }\end{array}$ & $\begin{array}{l}\text { - Switching value: emotional costs, performance costs (learning } \\
\text { costs, sunk costs) }\end{array}$ \\
\hline $\begin{array}{l}\text { Hou, Chern, } \\
\text { Chen, \& Chen, } \\
\text { (2009) }\end{array}$ & Online games & $\begin{array}{l}\text { PPM and other } \\
\text { references }\end{array}$ & $\begin{array}{l}\text { - (Push of the current: enjoyment, dissatisfaction with provider, and } \\
\text { insufficient participant) } \\
\text { - Moore: switching costs, social relationship, prior experience } \\
\text { - Pull of the alternative: attractiveness }\end{array}$ \\
\hline $\begin{array}{l}\text { Hou et al. } \\
\quad(2011)\end{array}$ & Online games & $\begin{array}{l}\text { PPM and other } \\
\text { references }\end{array}$ & $\begin{array}{l}\text { - Push of the current: (enjoyment, satisfaction, insufficient } \\
\text { participants) } \\
\text { - Moore: switching costs, need for variety, prior switching } \\
\text { experience, (social relationship) } \\
\text { - Pull of the alternative: attractiveness }\end{array}$ \\
\hline $\begin{array}{l}\text { Xu et al. } \\
(2013 a)\end{array}$ & $\begin{array}{l}\text { Social } \\
\text { networking } \\
\text { games }\end{array}$ & PPM & $\begin{array}{l}\text { - Push of the current: enjoyment } \\
\text { - Moore: adoption cost (sunk cost) } \\
\text { - Pull of the alternative: attractiveness, descriptive norm } \\
\text { - Age } \\
\text { - Gender }\end{array}$ \\
\hline $\begin{array}{l}\text { Xu et al. } \\
(2013 b)\end{array}$ & $\begin{array}{l}\text { Social } \\
\text { networking } \\
\text { games }\end{array}$ & $\begin{array}{l}\text { Various } \\
\text { references }\end{array}$ & $\begin{array}{l}\text { - Subjective norm } \\
\text { - Satisfaction } \\
\text { - Attractiveness } \\
\text { - Need for variety }\end{array}$ \\
\hline $\begin{array}{l}\text { Liu, Li, Xu, } \\
\text { Kostakos, \& } \\
\text { Heikkilä, } \\
\text { (2016) }\end{array}$ & $\begin{array}{l}\text { Social } \\
\text { networking } \\
\text { games }\end{array}$ & $\begin{array}{l}\text { Various } \\
\text { references }\end{array}$ & $\begin{array}{l}\text { - Attractiveness } \\
\text { - Service quality } \\
\text { - Satisfaction } \\
\text { - Change experience }\end{array}$ \\
\hline $\begin{array}{l}\text { Kim et al. } \\
(2006)\end{array}$ & $\begin{array}{c}\text { Email } \\
\text { services }\end{array}$ & $\begin{array}{l}\text { Various } \\
\text { references }\end{array}$ & $\begin{array}{l}\text { - Satisfaction with the current: stability, spam blocking, storage } \\
\text { capability (design) } \\
\text { - Availability of attractive alternatives } \\
\text { - Switching costs: continuity cost (setup cost) }\end{array}$ \\
\hline
\end{tabular}


Table A1. Review of IT Switching Studies

\begin{tabular}{|c|c|c|c|}
\hline $\begin{array}{l}\text { Park \& Ryoo } \\
(2013)\end{array}$ & $\begin{array}{l}\text { From desktop } \\
\text { to cloud } \\
\text { services }\end{array}$ & $\begin{array}{c}\text { Two-factor } \\
\text { theory }\end{array}$ & $\begin{array}{l}\text { - Switching benefits: omnipresence, collaboration support } \\
\text { - Switching costs: satisfaction with the current, breadth of use of the } \\
\text { current }\end{array}$ \\
\hline $\begin{array}{l}\text { Bhattacherjee } \\
\text { \& Park (2014) }\end{array}$ & $\begin{array}{l}\text { From desktop } \\
\text { to cloud } \\
\text { services }\end{array}$ & PPM & $\begin{array}{l}\text { - Push of the current: dissatisfaction } \\
\text { - Moore: learning cost, setup cost, security concerns } \\
\text { - Pull of the alternative: usefulness, omnipresence } \\
\text { - Other: subjective norm, self-efficacy }\end{array}$ \\
\hline $\begin{array}{l}\text { Hsieh, Hsieh, } \\
\text { Chiu, \& Feng } \\
\quad(2012)\end{array}$ & $\begin{array}{l}\text { From blogs to } \\
\text { social } \\
\text { network sites }\end{array}$ & $\begin{array}{l}\text { PPM and other } \\
\text { references }\end{array}$ & $\begin{array}{l}\text { - Push of the current: weak connection, writing anxiety } \\
\text { - Moore: switching cost, past experience } \\
\text { - Pull of the alternative: enjoyment, relative usefulness, (ease of } \\
\text { use) }\end{array}$ \\
\hline $\begin{array}{l}\text { Zhang et al. } \\
\qquad(2009)\end{array}$ & $\begin{array}{l}\text { Blog } \\
\text { providers }\end{array}$ & $\begin{array}{l}\text { Various } \\
\text { references }\end{array}$ & $\begin{array}{l}\text { - Satisfaction with the current } \\
\text { - Sunk costs } \\
\text { - Attractive alternatives } \\
\text { - Gender }\end{array}$ \\
\hline $\begin{array}{l}\text { Zhang et al. } \\
\qquad(2012)\end{array}$ & $\begin{array}{l}\text { Blog } \\
\text { providers }\end{array}$ & PPM & $\begin{array}{l}\text { - Push of the current: satisfaction with the current including stability, } \\
\text { charges, privacy, functionality, blogging culture, storage capacity, } \\
\text { ease of use } \\
\text { - Moore: sunk costs, descriptive and subjective norms, learning, } \\
\text { boredom } \\
\text { - Pull of the alternative: attractiveness of alternatives including } \\
\text { functionality, ease of use, readership, design, stability, storage } \\
\text { capacity }\end{array}$ \\
\hline
\end{tabular}




\section{About the Authors}

Markus Salo holds a doctoral degree in Information Systems (Econ.) from the University of Jyväskylä, Finland. His research interests include user behavior, technostress, and dark side of IT use. He has published completed research papers in outlets such as Information Systems Journal, Pervasive and Mobile Computing, International Journal of Human-Computer Interaction, and the International Conference on Information Systems (ICIS).

Markus Makkonen is a doctoral student at the Faculty of Information Technology, University of Jyväskylä, Finland. His research interests include the adoption and diffusion of information and communication technology (ICT) innovations, business models, business intelligence, and consumer behavior, especially in the context of electronic commerce, digital contents, and sport and wellness technologies. His research has been published in several information systems (IS) conferences and journals, such as the International Conference on Information Systems (ICIS), the European Conference on Information Systems (ECIS), the Americas Conference on Information Systems (AMCIS), and the Pacific Asia Conference on Information Systems (PACIS).

Copyright $@ 2018$ by the Association for Information Systems. Permission to make digital or hard copies of all or part of this work for personal or classroom use is granted without fee provided that copies are not made or distributed for profit or commercial advantage and that copies bear this notice and full citation on the first page. Copyright for components of this work owned by others than the Association for Information Systems must be honored. Abstracting with credit is permitted. To copy otherwise, to republish, to post on servers, or to redistribute to lists requires prior specific permission and/or fee. Request permission to publish from: AIS Administrative Office, P.O. Box 2712 Atlanta, GA, 30301-2712 Attn: Reprints or via email from publications@aisnet.org. 